\title{
5-Lumps kinetic modeling, simulation and optimization for hydrotreating of atmospheric crude oil residue
}

\author{
Sameer A. Esmaeel ${ }^{1} \cdot$ Saba A. Gheni ${ }^{2} \cdot$ Aysar T. Jarullah $^{1}$
}

Received: 30 June 2015/ Accepted: 24 November 2015/Published online: 17 December 2015

(c) The Author(s) 2015. This article is published with open access at Springerlink.com

\begin{abstract}
This research aims at developing a discrete kinetic model of the hydrotreating process of a crude oil residue based on experiments. Thus, various experiments were conducted in a continuous flow trickle bed reactor over a temperature range of $653-693 \mathrm{~K}$, liquid hourly space velocity of $0.3-1.0 \mathrm{~h}^{-1}$, and hydrogen pressure of 6.0-10.0 MPas at a constant hydrogen to oil ratio of $1000 \mathrm{~L} \mathrm{~L}^{-1}$. The reduced crude residue had been assumed to have five lumps: naphtha, kerosene, light gas oil, heavy gas oil and vacuum residue. An optimization technique based on the minimization of the sum of the squared error between the experimental and predicted compositions of the distillate fractions was used to calculate the optimal value of kinetic parameters. The predicted product composition showed good agreement with the experimental data for a wide range of operating conditions with a sum of square errors of less than $5 \%$.
\end{abstract}

Keywords Atmospheric residue - Hydrotreating (HDT) . Trickle bed reactor (TBR) $\cdot$ Lumping model

\section{List of symbols \\ $T \quad$ Temperature (K) \\ $r_{\mathrm{A}} \quad$ Rate of reaction $\left(\mathrm{wt} \% \mathrm{~h}^{-1}\right)$ \\ E Activation energy $\left(\mathrm{kJ} \mathrm{mol}^{-1}\right)$ \\ $k \quad$ Reaction rate constant $\left[(\mathrm{wt} \%)^{1-n} \mathrm{~h}^{-1}\right]$ \\ A Frequency factor $\left[(\mathrm{wt} \%)^{1-n} \mathrm{~h}^{-1}\right]$}

Saba A. Gheni

ghenis@missouri.edu

1 Chemical Engineering Department, Tikrit University, Tikrit, Iraq

2 Chemical Engineering Department, University of Missouri, Columbia, USA
$P \quad$ Pressure (Pas)

$P^{\circ} \quad$ Pressure reference (Pas)

LHSV Liquid hourly space velocity $\left(\mathrm{h}^{-1}\right)$

$\tau \quad$ Residence time (h)

$r_{\mathrm{R}} \quad$ Consumption rate of residue $\left(\mathrm{wt}_{\mathrm{R}} \% \mathrm{~h}^{-1}\right)$

$r_{\mathrm{HGO}}$ Consumption rate of heavy gasoil $\left(\mathrm{wt}_{\mathrm{HGO}} \% \mathrm{~h}^{-1}\right)$

$r_{\mathrm{LGO}} \quad$ Reaction rate of light gasoil $\left(\mathrm{wt}_{\mathrm{LGO}} \% \mathrm{~h}^{-1}\right)$

$r_{\mathrm{K}} \quad$ Reaction rate of kerosene $\left(\mathrm{wt}_{\mathrm{K}} \% \mathrm{~h}^{-1}\right)$

$r_{\mathrm{N}} \quad$ Reaction rate of naphtha $\left(\mathrm{wt}_{\mathrm{N}} \% \mathrm{~h}^{-1}\right)$

$k_{\mathrm{R}} \quad$ Reaction rate constant of residue $\left[\left(\mathrm{wt}_{\mathrm{R}} \%\right)^{1-n} \mathrm{~h}^{-1}\right.$ ]

$k_{\mathrm{HGO}} \quad$ Reaction rate constant of heavy gasoil [ $\left(\mathrm{wt}_{\mathrm{HGO}} \%\right)$ ${ }^{1-n} \mathrm{~h}^{-1}$ ]

$k_{\text {LGO }}$ Reaction rate constant of light gasoil $\left[\left(\mathrm{wt}_{\mathrm{LGO}} \%\right)^{1-n} \mathrm{~h}^{-1}\right]$

$k_{\mathrm{K}} \quad$ Reaction rate constant of kerosene $\left[\left(\mathrm{wt}_{\mathrm{K}} \%\right)^{1-n} \mathrm{~h}^{-1}\right]$

$k_{\mathrm{N}}$ Reaction rate constant of naphtha $\left[\left(\mathrm{wt}_{\mathrm{N}} \%\right)^{1-n} \mathrm{~h}^{-1}\right]$

$n \quad$ Reaction order (-)

$m \quad$ Deactivation rate order (-)

$k_{\mathrm{d}} \quad$ Deactivation rate constant $\left(\mathrm{h}^{-1}\right)$

$y_{\mathrm{R}} \quad$ Composition of residue fraction (wt\%)

$y_{\mathrm{HGO}}$ Composition of heavy gasoil fraction (wt $\%$ )

$y_{\mathrm{LGO}}$ Composition of light gasoil fraction (wt $\%$ )

$y_{K} \quad$ Composition of kerosene fraction (wt $\%$ )

$y_{N} \quad$ Composition of naphtha fraction (wt\%)

\section{Greek symbols}

$\Phi$ Catalyst activity

$\beta$ Order of pressure term in modified Arrhenius equation

\section{Symbols and abbreviations}

$R \quad$ Residue

HGO Heavy gas oil

LGO Light gas oil

K Kerosene 
$N \quad$ Naphtha

HDT Hydrotreating

\section{Introduction}

The upgrading of heavy crude oil residues to more valuable light and middle distillates is becoming increasingly important for the global refining industry because of the decline in conventional, light crude oil sources [1]. The hydrogenolysis is defined as the transformation of large hydrocarbon molecules (high boiling point) into smaller molecules (low boiling point) in the presence of hydrogen. In residue hydrotreatment, this transformation occurs due to the breaking of carboncarbon bonds or the removal of large atoms that is bonded to two unconnected pieces of hydrocarbon and has been used as one of the techniques for the upgrading of crude residues. For most of hydrotreating catalysts, the conversion rate is primarily a function of operating temperature, pressure and liquid hourly space velocity (LHSV) [2]. It is generally used to process heavy oil cuts. The process is tailored to various needs of refineries to maximize middle distillates, gasoline, LPG and similar products [3]. Kinetic model has a significant effect on process optimization, unit design and catalyst selection. Mathematical models for a trickle bed catalytic reactor can be complex due to many microscopic and macroscopic effects occurring inside the reactor, including flow patterns of both phases, size and shape of a catalyst particle, wetting of the catalyst pores with liquid phase, pressure drop, intraparticle gradients, thermal effects and, of course, kinetics on the catalyst surface [4]. Laxminarasimhan et al. [5] described a five-parameter continuous model for hydrocracking of heavy petroleum feedstocks that was subsequently used by Khorasheh et al. [6, 7] and Ashouri et al. [8] to describe the kinetics of hydrocracking, HDS, and HDN processes of bitumen. Today, there are two types of kinetic models available, detailed molecular models and lumped empirical models. The detailed molecular model is very accurate because it takes into account all possible reactions and mechanisms. Although the predictive power of detailed molecular models is much better than that of lumped empirical models, but their application to heavy feedstocks is very rare due to the complexity of the mixture. However, the available analytical techniques are incapable to identify the detailed molecular level of heavy feedstocks [9]. There are other types of modeling used to determine reactor performance such as hybrid modeling which is a first-principles model (FPM) based on the pseudo-component approach coupled with neural network(s) in different hybrid architectures [10], Combination of Genetic Algorithm and Sequential Quadratic Programming which based on genetic algorithm and sequential quadratic programming to determine the significant reactions and their corresponding rate constants [11], and some used kinetics to extract information about yield [12] and other model of hydrocracking reactor [13]. The lumped kinetic models are commonly used in modeling the hydrocracking of heavy feedstocks such as atmospheric vacuum resides. The lumped kinetic models have been classified into two types: discrete lumped models and continues lumped models. Specifying the chemical reactions involved in residual hydrocracking and the actual composition of the products is a complicated task. Therefore, the liquid product of residual upgrading is normally divided into several product lumps that are based on true boiling point temperature [14]. This is one approach to simplify the problem which considers the partition of the components into a few equivalent classes called lumps or lumping technique, and then assume each class as an independent entity [15]. The accuracy and the predictive power of discrete lumping models mainly depend on the number of lumps. As the amount of lumps increases, the predicted accuracy improves. Increasing the number of lumps, however, will complicate the model by increasing the number of model parameters [16]. Although numerous researchers published about lumping model for some oils and residues [3, 17-21], there is a lack of models for predicting kinetic parameters of atmospheric crude oil residue with a flexibility of operating pressure along with the absence of experimental data. The proposed model will estimate the optimal conditions of the five lumps, naphtha, kerosene, light gasoil, heavy gasoil and lowest residue with low content of impurities.

\section{Experimental work}

\section{Feedstock (reduced crude oil)}

The feedstock used in this study is an atmospheric crude residue (RCR) derived from Kirkuk crude oil as a crude model. It was obtained from the North Refineries Company in Iraq. The physical properties of the feedstock are illustrated in Table 1, which are tested in North Refineries Company laboratories.

\section{Hydrogen gas}

Hydrogen gas, $99.999 \%$ purity, has been used for hydrotreating of RCR. 
Table 1 The properties of feedstock (RCR)

\begin{tabular}{lll}
\hline Specification & Value \\
\hline Specific gravity at $15.6{ }^{\circ} \mathrm{C}$ & 0.9552 \\
API & 16.6 \\
Flash point & 95 \\
Pour point & +15 \\
Viscosity @ 50 ${ }^{\circ} \mathrm{C} / \mathrm{cst}$ & 223.1 \\
Viscosity @ $100{ }^{\circ} \mathrm{C} / \mathrm{cst}$ & 22.6 \\
Sulfur content & & $3.7 \%$ \\
\hline Distillation Vol.\% (D1160) & & \\
\hline Vol.\% & & \\
\hline IBP & & \\
5 & 335 & \\
10 & 352 & \\
20 & 375 & \\
30 & 428 & \\
40 & & \\
50 & & \\
60 & & \\
70 & 458 & \\
\hline
\end{tabular}

Table 2 Properties of (Ni-Mo/alumina) catalyst

\begin{tabular}{ll}
\hline & Value \\
\hline Chemical specification & \\
$\mathrm{Ni}$ & 12 \\
$\mathrm{Mo}$ & 6 \\
$\mathrm{SiO}_{2}$ & 1.2 \\
$\mathrm{Fe}$ & 0.67 \\
$\mathrm{Na}_{2} \mathrm{O}$ & 0.42 \\
$\mathrm{Al}_{2} \mathrm{O}_{3}$ & Balance \\
$\mathrm{Physical} \mathrm{specification}$ & \\
Form & Extrude \\
Bulk density $\left(\mathrm{g} \mathrm{cm}^{-3}\right)$ & 2.74 \\
Mean particle diameter $(\mathrm{mm})$ & 6.4 \\
Surface area $\left(\mathrm{m}^{2} \mathrm{~g}^{-1}\right)$ & 936 \\
\hline
\end{tabular}

\section{Catalyst}

The catalyst used in this study is a Ni-Mo supported on alumina that is a monofunctional catalyst and commonly used for HDT of heavy residue such as atmospheric residue. The specifications of catalyst are listed in Table 2.

\section{Apparatus}

The experiments of this study were conducted in an experimental scale, high temperature, and high-pressure

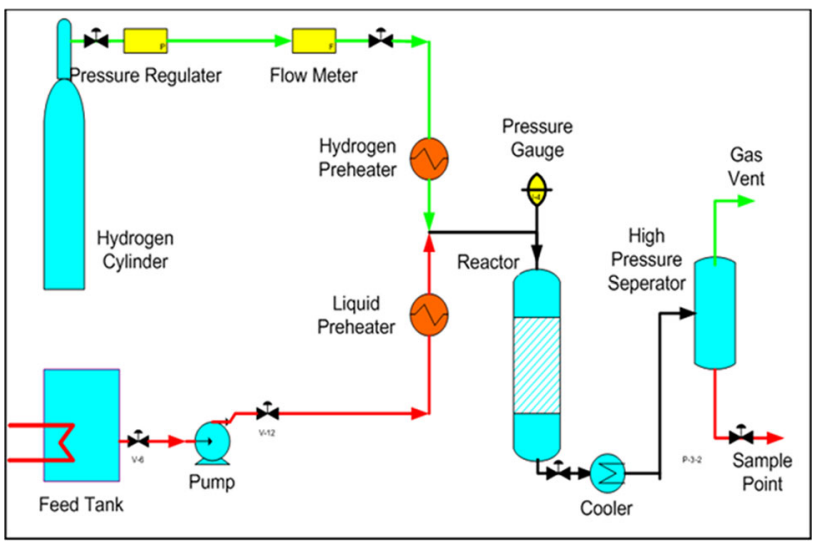

Fig. 1 Process flow diagram of trickle bed reactor unit

trickle bed reactor (TBR). Process flow diagram of this system is presented in Fig. 1. The continuous hydrotreating of RCR is carried out in the TBR where the feedstock and air pass through the reactor in cocurrently flow mode. The trickle bed reactor consists of a 316 stainless steel tubular reactor, $77 \mathrm{~cm}$ long, $1.5 \mathrm{~cm}$ internal diameter, and controlled automatically by four sections of $15-\mathrm{cm}$-high steel-jacket heaters. The first part of length (30-35\% vol.) was packed with inert particles. The second section ( $40 \%$ vol.) contained a packing of $\mathrm{Ni}$-Mo catalyst. The bottom section was also packed with inert particles of length (30-35\% vol.) to serve as disengaging section [22]. To ensure isothermal operation, the reactor had been heated, readings of temperature increase versus time were recorded and a good performance had been observed. Pre-RCR is stored in a $0.5 \mathrm{~m}^{3}$ feed tank with a coil heater connected to the tank that raise RCR temperature to $100{ }^{\circ} \mathrm{C}$ to maintain a liquid phase and avoid freezing. The feed tank is connected to a high-pressure dosing pump that can dispense flow rates from 0.0 to $0.07 \mathrm{~mm}^{3} \mathrm{~min}^{-1}$. Hydrogen flows from a high-pressure cylinder (15 MPa) equipped with a pressure controller to maintain constant operating pressure. The gas flow meter is coupled with a high-precision valve, which is used to control gas flow rate. The streams of hydrogen and RCR flow to separate electrical heaters (pre-heaters). The RCR and hydrogen gas streams are mixed and then introduced to the reactor at the required temperature when RCR is hydrotreated to the proposed products. The outlet from the reactor flows through a heat exchanger to a high-pressure gas-liquid separator to separate excess hydrogen from the petroleum products and $\mathrm{H}_{2} \mathrm{~S}$ from liquid product, which is withdrawn from sample points when reaction reaches the steady state. Table 3 shows the description and specifications of TBR unit and its constituents Fig. 2 shows the factors affect the operation of trickle bed reactor. 
Table 3 Experimental device description and specifications

\begin{tabular}{ll}
\hline Description & Specification \\
\hline $\begin{array}{l}\text { Feed tank (containing } \\
\text { RCR) }\end{array}$ & Box, $0.008 \mathrm{~m}^{3}$ \\
Compressor & $13 \mathrm{MPa}$ \\
Pre-heater & Electrical coil \\
Pump & Dosapro Milton Roy/Italy \\
& Max flow $=0.00127 \mathrm{~m}^{3} \mathrm{~h}^{-1}$ \\
& Max. pressure $=12 \mathrm{MPa}^{-1}$ \\
Trickle bed reactor(TBR) & Stainless steel 310 \\
& $1.6 \mathrm{~cm} \times 73 \mathrm{~cm}$ \\
Control box & Control box \\
Reactor heating jacket & Electrical coils \\
Heat exchanger (cooler) & Shell and tube (four tubes) stainless \\
& steel \\
Separator & Stainless steel \\
Pressure gauge & Neu-tec/Italy \\
Gas flow meter & $0-12.5 \mathrm{MPas}$ \\
& Yamamoto \\
Cooling water & $0-0.006 \mathrm{~m}^{3} / \mathrm{min}$ \\
\hline
\end{tabular}

\section{Experimental procedure}

\section{Operating conditions}

The major effect of operational variables employed in TBR unit and their influence on the reactor performance can be summarized as follows. To improve the dibenzothiophene conversion, three procedures can be chosen: increase of temperature (653-693 K), decrease of liquid hour space velocity LHSV $\left(0.3-1 \mathrm{~h}^{-1}\right)$ and increase of pressure (6-10 MPa) at a constant hydrogen to oil ratio (1000) over nickel-molybdenum $\left(\mathrm{Ni}-\mathrm{Mo} / / \gamma-\mathrm{Al}_{2} \mathrm{O}_{3}\right)$.

\section{Experimental runs}

The hydrotreating experiments were carried out in a continuous isothermal trickle bed reactor packed with $40 \% \mathrm{Ni}-\mathrm{Mo} / / \gamma-\mathrm{Al}_{2} \mathrm{O}_{3}$ of the catalyst particles. The model reduced crude oil is Kirkuk crude oil which is obtained from the North Refineries Company, Iraq. The cooling water is flowing through the heat exchanger and the temperature of the cooling jackets is maintained below $293 \mathrm{~K}$ to prevent vaporization of light components present in reduced crude and nitrogen gas is flown through the system to check leaks and to get rid of any remaining gases and liquid from the previous run. Reduced crude oil mixed with hydrogen is flown through the reactor at 0.2 MPas pressure and temperature controller is set to the

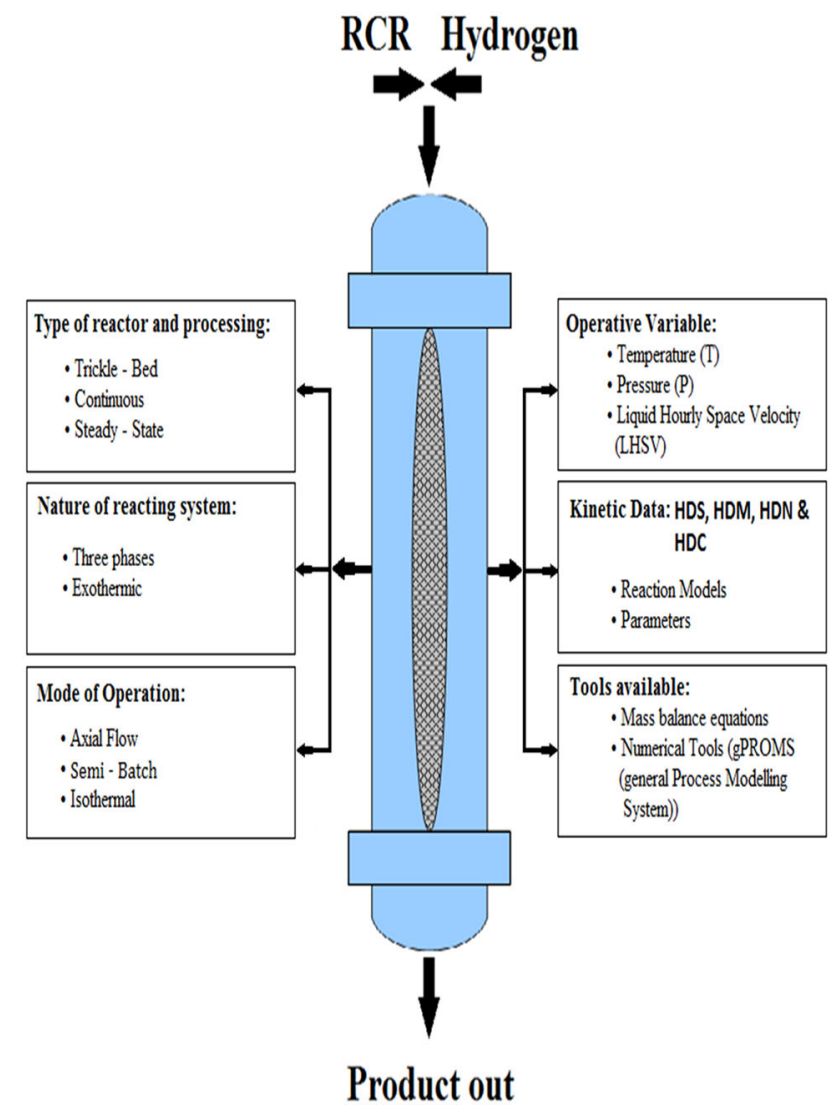

Fig. 2 Variables affect operation of trickle bed reactor for hydrocracking of RCR

feed injection temperature (it is lower than steady-state operating temperature). When the temperature of air reaches feed injection temperature the dosing pump is turned on to allow a certain reduced crude oil flow rate and the temperature is raised at the rate of $293 \mathrm{~K} \mathrm{~h}^{-1}$ until the steady-state temperature is reached. At the end of a run, the RCR dosing pump is turned off keeping air gas flow on to back wash any remaining light gas oil. Finally, the air valve is closed and nitrogen is passed through the system to remove the remaining air and to get the system ready for the next run.

\section{Laboratory tests}

There are many tests in this work, the analysis tests of products can be divided into two types, one for gas product and the other for liquid product. The primary tests of hydrotreating products revealed insignificant gases concentration of less than $0.124 \%$ (a constant concentration, selectivity, of the products gases have been observed during experimentations). Thus, all the products analyzed and modeled in this study are liquids. The tests applied to the products of this work are as following: 
True boiling point distillation Feed and products are distillated by ASTM D1160 Vacuum Distillation Apparatus for distillation of petroleum products.

Sulfur content Feed and products sulfur content are tested by ASTM D2622 (X-RAY Spectrometer ARL OPTIM'X from Thermo Scientific). This test method provides rapid measurement of total sulfur in petroleum and petroleum products with a minimum of sample preparation. A typical analysis time is 1-2 min per sample.

\section{Mathematical model of TBR for hydrotreating reaction}

Process model is very profitable and is utilized for operator training, safety systems design, design of operation and operational control systems designs. The improvement of faster computer and sophisticated numerical methods has enabled modeling and solution of the whole operation [23]. Many authors have reported that pore diffusion effects can be taken into account within the framework of an effective or apparent reaction rate constant (i.e., multiplying intrinsic reaction rate constant by effectiveness factor), in order to formulate a pseudo homogeneous basic plug flow model which is sufficient to describe the progress of chemical reactions in the liquid phase of a TBR [24-26]. The required data and available tools with the assumptions for modeling and simulation processes RCR hydrotreating are tabulated in Fig. 3.

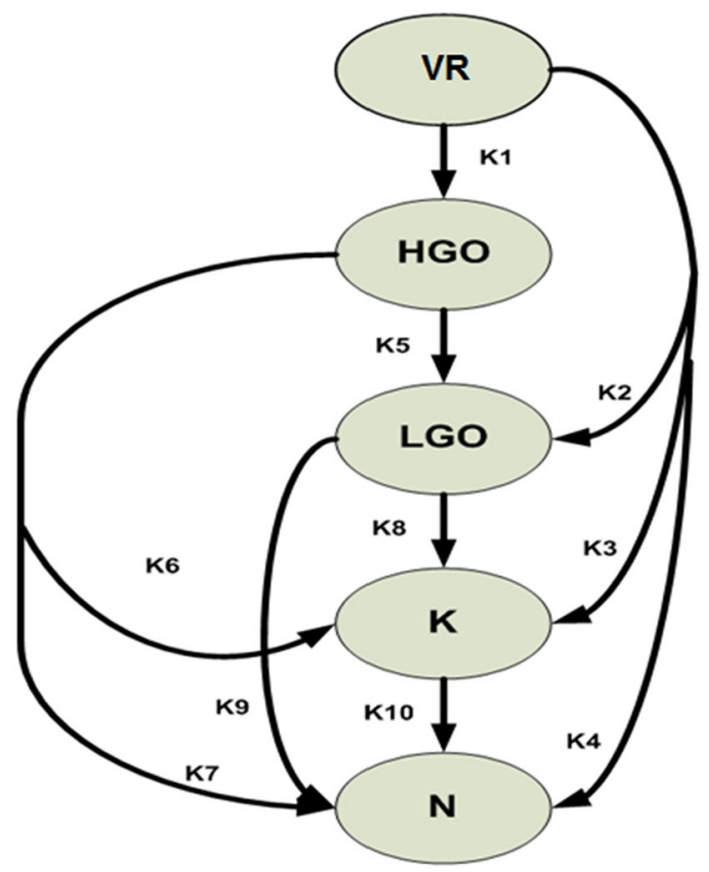

Fig. 3 General expectation of reaction pathways of RCR hydrocracking
Table 4 True boiling range of the lumps

\begin{tabular}{ll}
\hline Fractions & TBP range $\left({ }^{\circ} \mathrm{C}\right)$ \\
\hline Naphtha $(N)$ & IBP-433 \\
Kerosene $(K)$ & $433-528$ \\
Light gas oil (LGO) & $528-618$ \\
Heavy gas oil (HGO) & $618-813$ \\
Vacuum residue (VR) & $>813$ \\
\hline
\end{tabular}

\section{Discrete lumping model}

In this study, we considered the conversion of atmospheric residue to generate five product lumps that are characterized by various true boiling point temperature (TBP) range. In this respect, the five fractions are: naphtha $(N)$, kerosene $(K)$, light gas oil (LGO), heavy gas oil (HGO) and vacuum residue (VR). The boiling ranges of these fractions are given in Table 4 . The vacuum residue in these lumps represents the amount of unconverted feed while the naphtha, kerosene, light and heavy gas oil are complex mixtures of hydrocarbons that have resulted from conversion. Naphtha fraction is poorly generated in residue hydro-processing. Kerosene is a highly demanded fraction due to demand for kerosene as a domestic heating fuel. The gas oil fractions are an important cut that is mainly used for the production of transportation fuels. The vacuum residue fraction has a very low demand and it is known for its deteriorating effects on the catalyst of downstream processes such as fluid catalytic cracking. Figure 3 illustrates reaction pathways with weight fraction. Note if all pathways of reactions were considered, the model would include twenty-one kinetic parameters. All these parameters should be estimated from experimental data, and it was too laborious.

\section{Kinetic model}

Due to the complexity of mathematical models for a trickle bed catalytic reactor, it is more practical to reduce the complexity of the reactor, focusing only on momentous process variables. This suggests a development of simpler models that incorporates less number of parameters. For each reaction, a kinetic expression $(R)$ is formulated as a function of mass concentration $(C)$ and kinetic parameters $\left(k_{0}, E\right)$. The following assumptions have been made in the development of the present model:

1. Modified Arrhenius equation applied for each reaction.

2. Hydrotreating is a first-order hydrotreating reaction. Since hydrogen is present in excess, the rate of hydrotreating can be considered independent of hydrogen concentration [27].

3. The reactor operates under isothermal condition. 
4. The trickle bed reactor follows a plug flow pattern. Axial dispersion, external and internal gradients are neglected.

5. The feed gas, hydrogen, is pure.

6. The petroleum feed and the products are in liquid phase in the reactor.

7. The experimental unit is working under steady-state operation.

Based on these assumptions, the kinetic constants of the proposed model are:

Residue $(F)$ :

$k_{F j}=\varphi k_{o F j} \exp \left(\frac{-E_{F j}}{\mathrm{RT}}\right)\left(\frac{P}{P_{O}}\right)^{\beta}$

Note: $j$ in Eq. 1 represents heavy gas oil (HGO), light gas oil (LGO), kerosene $(K)$ and naphtha $(N)$ lumps.

Heavy gasoil (HGO):

$k_{\mathrm{HGO} j^{\prime}}=\varphi k_{o \mathrm{HGO}^{\prime}} \exp \left(\frac{-E_{\mathrm{HGO}^{\prime}}}{\mathrm{RT}}\right)\left(\frac{P}{P_{O}}\right)^{\beta}$

where $j^{\prime}$ represents light gas oil (LGO), kerosene (K) and naphtha $(\mathrm{N})$ lumps.

Light gasoil (LGO):

$k_{\mathrm{LGO}^{\prime \prime}}=\varphi k_{o \mathrm{LGO}^{\prime \prime}} \exp \left(\frac{-E_{\mathrm{LGO}^{\prime \prime}}}{\mathrm{RT}}\right)\left(\frac{P}{P_{O}}\right)^{\beta}$

where $j^{\prime \prime}$ are kerosene $(K)$ and naphtha $(N)$ lumps.

Kerosene $(K)$ :

$k_{K N}=\varphi k_{o K N} \exp \left(\frac{-E_{K N}}{\mathrm{RT}}\right)\left(\frac{P}{P_{O}}\right)^{\beta}$

$T$ and $R$ are the absolute value of bed temperature and ideal gas constant, respectively, and $\varphi$ represents the deactivation rate, it is represented by:

$\varphi=1 /\left(1+k_{\mathrm{d}} t\right)^{m}$

The reaction rates $(R)$ can be formulated as follows:

$R_{F}=\sum_{j=\mathrm{HGO}}^{N} k_{F: j} y_{F}$

Heavy gasoil $\left(R_{\mathrm{HGO}}\right)$ :

$R_{\mathrm{HGO}}=k_{F: \mathrm{HGO}} y_{F}-\sum_{j=\mathrm{LGO}}^{N} k_{\mathrm{HGO} j} y_{\mathrm{HGO}}$

Light gasoil $\left(R_{\mathrm{LGO}}\right)$ :

$R_{\mathrm{LGO}}=k_{F: \mathrm{LGO}} y_{F}+k_{\mathrm{HGO}: \mathrm{LGO}} y_{\mathrm{HGO}}-\sum_{j=K}^{N} k_{\mathrm{LGO}: j} y_{\mathrm{LGO}}$

Kerosene $\left(R_{K}\right)$ :

$R_{K}=k_{F: K} y_{F}+k_{\mathrm{HGO}: K} y_{\mathrm{HGO}}+k_{\mathrm{LGO}: K} y_{\mathrm{LGO}}$

$$
-k_{K: N} C_{N}
$$

Naphtha $\left(R_{N}\right)$ :

$$
\begin{array}{r}
R_{K}=k_{F: K} y_{F}+k_{\mathrm{HGO}: K} y_{\mathrm{HGO}}+k_{\mathrm{LGO}: K y_{\mathrm{LGO}}} \\
+k_{K: N} C_{N}
\end{array}
$$

The set of equations from 1 to 10 were coded and solved simultaneously using the gPROMS [28].

\section{Parameter estimation techniques}

Parameter estimation is necessary in several fields of science and engineering as many physiochemical processes are described by systems equations with unown parameters. Recently, the benefits of developing kinetic models for chemical engineers with accurate parameter calculations have increased owing to the developed control technologies and optimization of process, which can apply fundamental models [29]. Estimation of kinetic parameters is an important and difficult step in the development of models, but calculations of unknown kinetic parameters can be achieved by utilizing experimental data and model-based technique. When estimating kinetic parameters of the models, the goal is to calculate appropriate parameter values so that errors between experimental and theoretical data (based on mathematical model) are minimized. On the other hand, the predicted values from the model should match the experimental data as closely as possible [29]. For the purpose of process optimization, design of reactor and process control, it is important to develop kinetic models that can accurately predict the concentration of product under process conditions.

The experimental data of hydrotreating reaction were adjusted with a simple power law kinetic model. Plug flow behavior was considered, and the reaction

$\frac{\mathrm{d} y_{i}}{\mathrm{~d} \tau}=-k y_{j}^{n}$.

where $y_{i}$ is the yield weight fraction of $i$ lump in reaction products, $\tau$ the residence time $(\tau=1 / L H S V), k$ the global rate constant, and $n$ the reaction order of residue hydrotreating.

Yields were determined by integration of Eq. 11, where $y_{i o}$ is the initial weight fraction of $i$ lump in the feed:

$y_{i}^{\text {calc. }}=\left[y_{i o}^{1-n}+k \tau(n-1)\right]^{1 /(1-n)}$

For parameter estimation, the objective function, OBJ, as given below, as minimized:

OBJ. $=\sum_{n=1}^{N_{\mathrm{t}}} \sum_{j=F}^{n} w_{j}\left(y_{j n}^{\text {meas. }}-y_{j n}^{\text {prid. }}\right)^{2}$.

where $N_{\mathrm{t}}$ is the number of test runs, $y_{i}^{\exp }$ is the weight fraction measured experimentally of $i$ lump and $y_{i}^{\text {esti }}$ is the weight fraction estimated by the model of $i$ lump, in the 
products. Reactions and expressions in Eqs. 1 through 13 were coded and solved simultaneously using General PROcess Modeling System (gPROMS) programming environment to evaluate the product yields $\left(y_{i}\right)$. According to the initial suggestion of kinetic parameters from previous works, the composition of all fractions has been estimated by application of model equations in gPROMS.

\section{Optimization problem formulation}

The optimization problem formulation for parameter estimation can be stated as follows:

Given The reactor configuration, the feedstock, the catalyst, reaction temperature, hydrogen pressure and liquid hourly space velocity;

Obtained The reaction orders of cracking of residue, HGO, LGO and kerosene $\left(n_{1}, n_{2}, n_{3}\right.$ and $\left.n_{4}\right)$ and deactivation rate order $(m)$, reaction rate constants $\left(k_{\mathrm{i}}\right)$ at different temperatures, pressures and LHSVs and deactivation rate constant $\left(k_{\mathrm{d}}\right)$ at different temperatures, pressure-dependent parameter $(\beta)$.

So as to minimize The sum of square errors (SQE).

$\mathrm{SQE}=\sum_{n=1}^{N_{\mathrm{t}}} \sum_{j=F}^{G} W_{j} \cdot\left(Y_{j n}^{\mathrm{meas}}-Y_{j i}^{\mathrm{pred}}\right) 2$

In Eq. $14, N_{\mathrm{t}}, Y_{j n}^{\text {meas }}$ and $Y_{j n}^{\text {pred }}$ are the numbers of test runs, the measured product yield and the predicted one by model, respectively

Subject to Process constraints and linear bounds on all optimization variables in the process.

Mathematically, the problem can be presented as:

\begin{tabular}{ll}
\hline Min & SSE \\
\hline$k, k_{\mathrm{d}}, n, m, \beta$ & \\
$\begin{array}{l}\text { s.t } f(t, x(t), x \sim(t), \\
u(t))=0\left[t_{0}, t_{f}\right]\end{array}$ & (model equality constraints) \\
$k_{i j}^{L} \leq k_{i j}^{U}$ & {$[i=1,2,3, \ldots 10 ; j=0,1,2$} \\
& for each pressure $]$ \\
& Inequality constraints \\
$k_{\mathrm{d}}^{L} \leq k_{\mathrm{d}}^{U}$ & Inequality constraints \\
$n^{L} \leq n^{U}$ & Inequality constraints \\
$m^{L} \leq m^{U}$ & Inequality constraints \\
$\beta^{L} \leq \beta^{U}$ & Inequality constraints
\end{tabular}

$f(t, x(t), x \sim(t), u(t))=0$ represents the process model, where $t$ is the independent variable (time), $x(t)$ gives the set of all differential and algebraic variables, $x \sim(t)$ denotes the derivative of differential variables with respect to time, $u(t)$ is the control variable. Initial and final time of reaction is $\left[t_{0}, t_{f}\right]$ and the function $f$ is assumed to be continuously differentiable with respect to all its arguments.
The optimization solution method used by gPROMS is a two-step method known as a feasible path approach. The first step performs the simulation to converge all the equality constraints (described by $f$ ) and to satisfy the inequality constraints. The second step performs the optimization (updates the values of the decision variables such as the kinetic parameters). The optimization problem is posed as a NonLinear Programming (NLP) problem and is solved using a Successive Quadratic Programming (SQP) method within gPROMS (see Jarullah et al. [30-32] for further details).

\section{Results and discussion}

\section{Experimental results}

\section{Effect of catalyst on process conversion at operating} conditions

The effect of metal oxide loading, reaction temperature, LHSV and initial concentration on the process conversion

Table 5 Hydrocracking results

\begin{tabular}{|c|c|c|c|c|c|c|c|}
\hline LHSV & Press. & Temp. & Naphtha & Kero. & LGO & VGO & VR \\
\hline 0.3 & 60 & 380 & 1.279 & 1.193 & 7.336 & 55.971 & 34.221 \\
\hline 0.7 & 60 & 380 & 0.801 & 0.709 & 5.002 & 54.002 & 39.486 \\
\hline 1 & 60 & 380 & 0.618 & 0.548 & 4.002 & 53.067 & 41.765 \\
\hline 0.3 & 60 & 400 & 2.328 & 1.401 & 8.453 & 57.091 & 30.727 \\
\hline 0.7 & 60 & 400 & 1.519 & 0.961 & 6.032 & 55.345 & 36.143 \\
\hline 1 & 60 & 400 & 1.201 & 0.756 & 4.981 & 54.344 & 38.718 \\
\hline 0.3 & 60 & 420 & 2.986 & 2.096 & 10.939 & 60.014 & 23.965 \\
\hline 0.7 & 60 & 420 & 1.995 & 1.455 & 8.013 & 57.176 & 31.361 \\
\hline 1 & 60 & 420 & 1.689 & 1.198 & 6.654 & 56.211 & 34.248 \\
\hline 0.3 & 80 & 380 & 1.626 & 1.398 & 7.942 & 56.174 & 32.86 \\
\hline 0.7 & 80 & 380 & 0.965 & 0.832 & 5.131 & 54.408 & 38.664 \\
\hline 1 & 80 & 380 & 0.755 & 0.672 & 4.121 & 53.429 & 41.023 \\
\hline 0.3 & 80 & 400 & 2.503 & 1.717 & 8.811 & 58.532 & 28.437 \\
\hline 0.7 & 80 & 400 & 1.691 & 1.159 & 6.215 & 56.728 & 34.207 \\
\hline 1 & 80 & 400 & 1.318 & 0.936 & 5.069 & 55.179 & 37.498 \\
\hline 0.3 & 80 & 420 & 3.486 & 2.589 & 11.308 & 60.761 & 21.856 \\
\hline 0.7 & 80 & 420 & 2.485 & 1.794 & 8.109 & 58.037 & 29.575 \\
\hline 1 & 80 & 420 & 1.998 & 1.602 & 6.981 & 57.781 & 31.638 \\
\hline 0.3 & 100 & 380 & 1.978 & 1.641 & 8.059 & 56.476 & 31.846 \\
\hline 0.7 & 100 & 380 & 1.204 & 1.021 & 5.332 & 54.872 & 37.571 \\
\hline 1 & 100 & 380 & 0.921 & 0.821 & 4.301 & 54.292 & 39.665 \\
\hline 0.3 & 100 & 400 & 2.877 & 2.033 & 9.225 & 58.997 & 26.868 \\
\hline 0.7 & 100 & 400 & 2.001 & 1.406 & 6.467 & 56.811 & 33.315 \\
\hline 1 & 100 & 400 & 1.618 & 1.188 & 5.189 & 55.991 & 36.014 \\
\hline 0.3 & 100 & 420 & 3.756 & 3.141 & 11.397 & 61.165 & 20.541 \\
\hline 0.7 & 100 & 420 & 2.764 & 2.112 & 8.385 & 58.897 & 27.842 \\
\hline 1 & 100 & 420 & 2.198 & 1.798 & 7.105 & 58.048 & 30.856 \\
\hline
\end{tabular}


Fig. 4 Effect of temperature on hydrocracking yields at constant 10 MPas and different LHSVs a 0.3 , b 0.7 and $\mathbf{c} 1.0 \mathrm{~h}^{-1}$
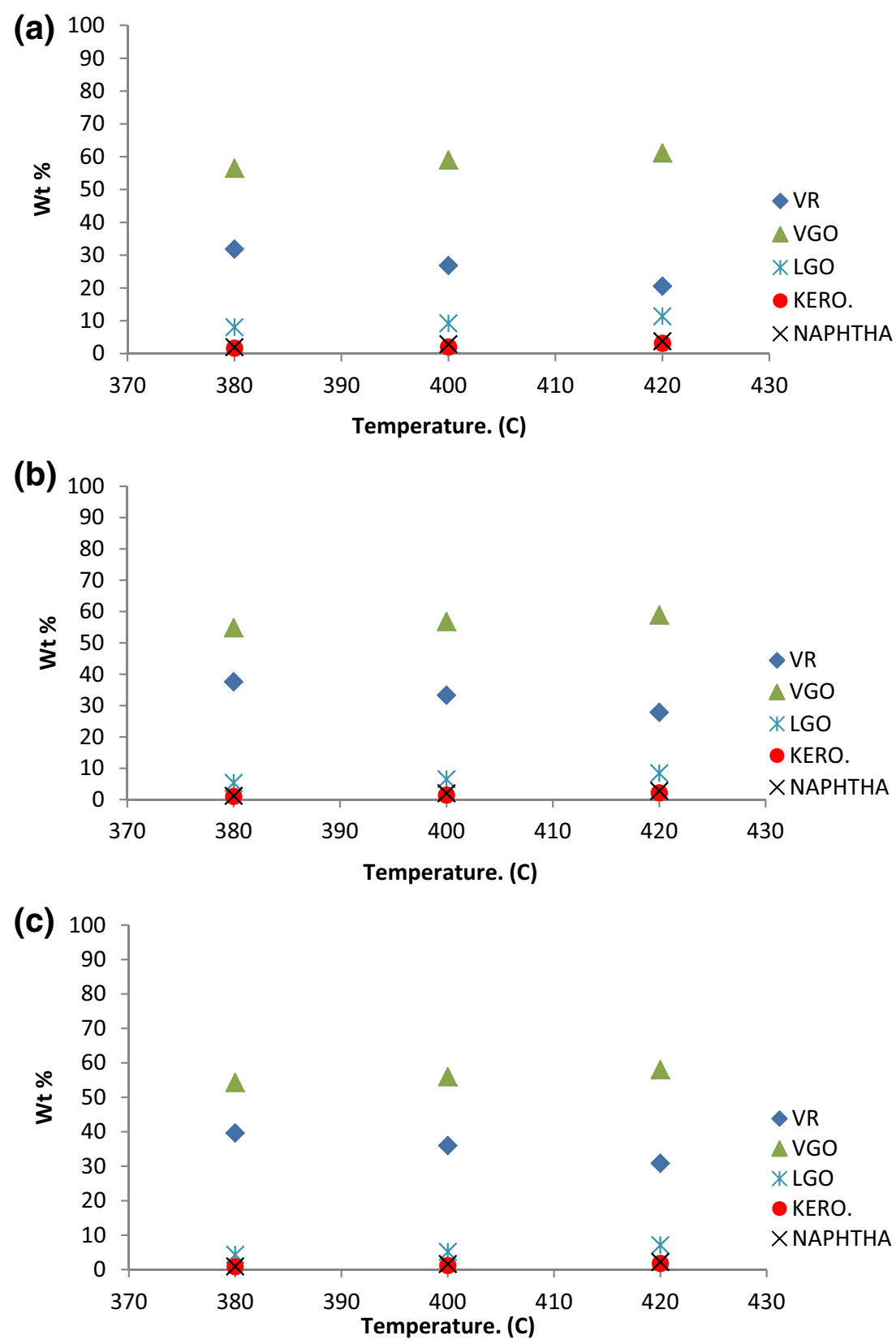

is investigated. The yields of naphtha $(N)$ are normally very low in residue hydrogenolysis. The kerosene $(K)$ fraction is normally the most significant hydrotreated products of the residue hydrogenolysis. The gasoil fraction (GO) is an important cut because it is used as a feedstock for fluid catalytic cracking and hydrocracking, which are mainly operated for the production of transportation fuels. The demand for the vacuum residue (VR) is very low due to its deteriorating effects on the downstream processes such as fluid catalytic cracking (FCC). The atmospheric residue of the model crude oil consists of no naphtha and kerosene,
$0.527 \mathrm{wt} \%$ light gas oil, 51.345 and $48.128 \mathrm{wt} \%$. Below $653 \mathrm{~K}$ high conversion has not been observed on the processes. There was also no significant difference in conversion for the hydrotreating of model RCR catalyzed by temperature of $653 \mathrm{~K}$ and LHSV of $1 \mathrm{~h}^{-1}$. The optimal results were obtained with a temperature of $693 \mathrm{~K}$, LHSV of $0.3 \mathrm{~h}^{-1}$ and $10 \mathrm{MPas}$. The results of experimental runs are shown in Table 5.

As a result of studying fractions data listed in Table 5, the domination of catalyst hydrotreating over thermal cracking is confidently concluded. This conclusion is based 
Fig. 5 Effect of LHSV on hydrocracking yields at constant pressure at 10 MPas bar and different temperatures a 380 , b 400 and c $420{ }^{\circ} \mathrm{C}$
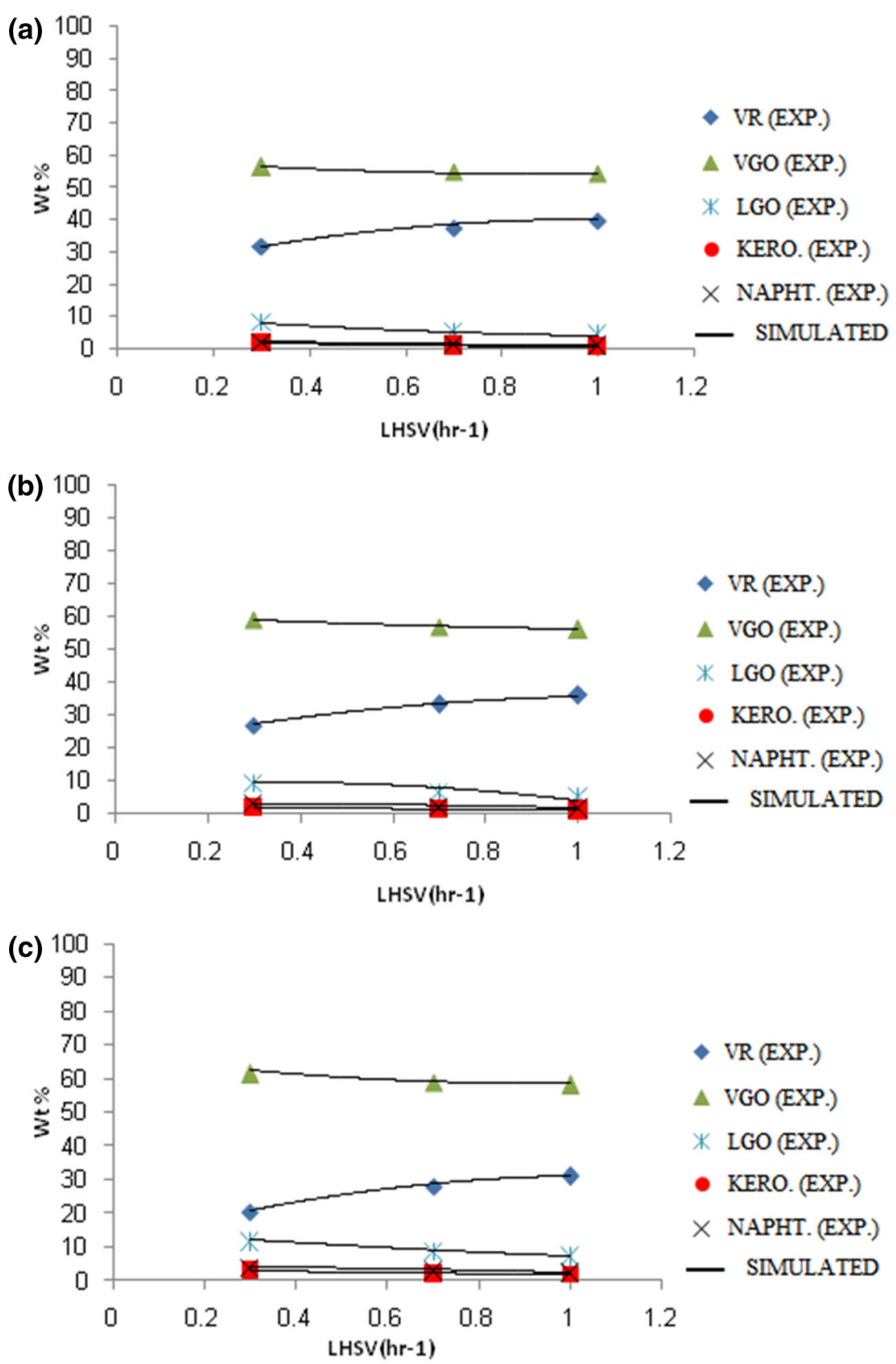

on two main observations. The first one is the suppression of gas formation, while the second observation is the selectivity towards kerosene formation. It is known that thermal cracking yields huge amounts of light products and gases. On the contrary, experimental data revealed that very low concentration of naphtha were obtained. Table 5 shows that the highest concentration of naphtha fraction is $3.756 \mathrm{wt} \%$. This concentration was achieved at the highest severity. Another indication of catalytic domination is the selectivity toward kerosene and light gasoil production, this selectivity has resulted from the high concentration of molybdenum in the catalyst [33].

\section{Effect of temperature on process conversion}

The hydrotreating reactivity of RCR was also investigated at different temperatures $(653-693 \mathrm{~K}$, and different LHSV $\left(0.3-1 \mathrm{~h}^{-1}\right)$, in the presence of the $\left(\mathrm{Ni}-\mathrm{Mo} / \gamma-\mathrm{Al}_{2} \mathrm{O}_{3}\right)$ catalyst. The effects of LHSV and temperature on hydrogenolysis reactions are shown in Fig. 4. At low temperature, the conversion of RCR was very low, then increased gradually with increasing reaction temperature from 653 to $693 \mathrm{~K}$. The yield of naphtha and kerosene was decreased by increasing the LHSV which agreed with the role of the smaller the LHSV, the better the hydrotreating [34]. The role of 

hydrocracking yields at constant temperature at $420{ }^{\circ} \mathrm{C}$ and different LHSVs a 0.3 , b 0.7 and $\mathbf{c} 1.0 \mathrm{~h}^{-1}$
Fig. 6 Effect of pressure on
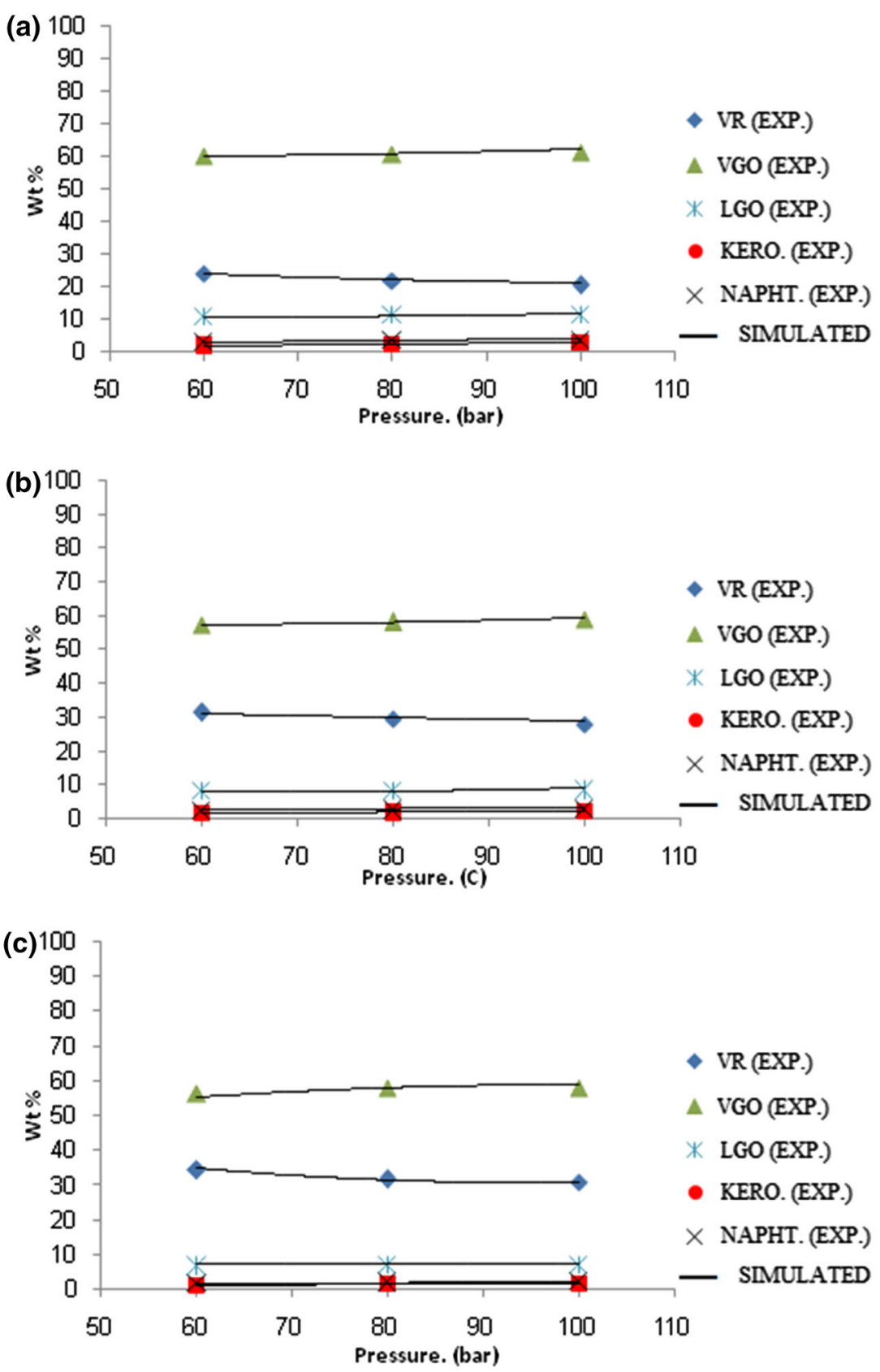

temperature was routine, for naphtha and kerosene the undesirable in an industrial scale because of the problems of deactivation of the catalyst.

\section{Effect of LHSV on process conversion}

The effect of LHSV on hydrogenolysis yields is presented in Fig. 5. It can be seen, increasing LHSV has an adverse impact on RCR cracking. Figure 5 depicts the effect of liquid flow rate on RCR cracking. As clearly noted from this figure, a high yield of light fraction is obtained at 
LHSV $=0.3 \mathrm{~h}^{-1}$. Note, at LHSV of 0.7 and $1 \mathrm{~h}^{-1}$, the yield was lower. Actually, increasing liquid flow rate reduces the residence time of the reactant thus reducing reaction time of RCR with hydrogen (gas reactant). Moreover, higher liquid flow rate gives greater liquid

Table 6 Optimal model parameters obtained by optimization process

\begin{tabular}{lll}
\hline Parameter & Value & Units \\
\hline$n_{1}$ & 1.1662 & $(-)$ \\
$n_{2}$ & 1.9892 & $(-)$ \\
$n_{3}$ & 1.9936 & $(-)$ \\
$n_{4}$ & 1.023 & $(-)$ \\
$m$ & 0.4207 & $(-)$ \\
$k_{\mathrm{d} 1}$ & 1.4448 & $\mathrm{~h}^{-1}$ \\
$k_{\mathrm{d} 2}$ & 3.6917 & $\mathrm{~h}^{-1}$ \\
$k_{\mathrm{d} 3}$ & 6.8324 & $\mathrm{~h}^{-1}$ \\
$\beta$ & 0.0177 & $(-)$ \\
\hline
\end{tabular}

Table 7 Comparison between experimental product composition and predicted product composition of atmospheric residue (RCR)

\begin{tabular}{|c|c|c|c|c|c|}
\hline LHSV & Press. & Temp. & Predicted & Experimental & Error\% \\
\hline 0.3 & 60 & 380 & 33.944 & 34.221 & 0.809 \\
\hline 0.7 & 60 & 380 & 41.333 & 39.486 & 4.677 \\
\hline 1 & 60 & 380 & 43.246 & 41.765 & 3.546 \\
\hline 0.3 & 60 & 400 & 33.377 & 30.727 & 8.624 \\
\hline 0.7 & 60 & 400 & 41.025 & 36.143 & 13.507 \\
\hline 1 & 60 & 400 & 43.019 & 38.718 & 11.108 \\
\hline 0.3 & 60 & 420 & 31.851 & 23.965 & 32.906 \\
\hline 0.7 & 60 & 420 & 40.18 & 31.361 & 28.121 \\
\hline 1 & 60 & 420 & 42.392 & 34.248 & 23.779 \\
\hline 0.3 & 80 & 380 & 30.502 & 32.86 & 7.176 \\
\hline 0.7 & 80 & 380 & 39.41 & 38.664 & 1.929 \\
\hline 1 & 80 & 380 & 41.816 & 41.023 & 1.933 \\
\hline 0.3 & 80 & 400 & 24.088 & 28.437 & 15.293 \\
\hline 0.7 & 80 & 400 & 35.412 & 34.207 & 3.522 \\
\hline 1 & 80 & 400 & 38.763 & 37.498 & 3.373 \\
\hline 0.3 & 80 & 420 & 28.463 & 21.856 & 30.229 \\
\hline 0.7 & 80 & 420 & 38.204 & 29.575 & 29.176 \\
\hline 1 & 80 & 420 & 40.906 & 31.638 & 29.294 \\
\hline 0.3 & 100 & 380 & 22.044 & 31.846 & 30.779 \\
\hline 0.7 & 100 & 380 & 33.996 & 37.571 & 9.515 \\
\hline 1 & 100 & 380 & 37.653 & 39.665 & 5.072 \\
\hline 0.3 & 100 & 400 & 27.038 & 26.868 & 0.632 \\
\hline 0.7 & 100 & 400 & 37.327 & 33.315 & 12.042 \\
\hline 1 & 100 & 400 & 40.239 & 36.014 & 11.731 \\
\hline 0.3 & 100 & 420 & 21.044 & 20.541 & 2.452 \\
\hline 0.7 & 100 & 420 & 33.272 & 27.842 & 19.502 \\
\hline 1 & 100 & 420 & 37.081 & 30.856 & 20.174 \\
\hline
\end{tabular}

holdup, which evidently decreases the contact of liquid and gas reactants at the catalyst active site, by increasing film thickness. Figure 5 also illustrates that the yield of naphtha and kerosene was decreased by increasing the LHSV which was in agreement with the role of the residence time- the smaller the LHSV, the better the hydrotreating [3]. The small difference in conversion between LHSV $=0.3$ and LHSV $=1$ is attributed to the effect on hydrogen consumption. The hydrogen consumption increased sharply with temperature, but LHSV does not have any sensible variation on it. The hydrogen consumption is a little higher at lower LHSVs (LHSV less than 1).

\section{Effect of pressure on process conversion}

The effect of pressure on hydrogenolysis yields is presented in Fig. 6. It can be seen, increasing pressure has a significant impact on RCR cracking. The effect of pressure

Table 8 Comparison between experimental product composition and predicted product composition of heavy gas oil (HGO)

\begin{tabular}{|c|c|c|c|c|c|}
\hline LHSV & Press. & Temp. & Predict. & Experiment & Error\% \\
\hline 0.3 & 6.0 & 380 & 56.269 & 55.971 & 0.532 \\
\hline 0.7 & 6.0 & 380 & 53.704 & 54.002 & 0.551 \\
\hline 1 & 6.0 & 380 & 53.039 & 53.067 & 0.052 \\
\hline 0.3 & 6.0 & 400 & 55.953 & 57.091 & 1.993 \\
\hline 0.7 & 6.0 & 400 & 53.563 & 55.345 & 3.219 \\
\hline 1 & 6.0 & 400 & 52.94 & 54.344 & 2.583 \\
\hline 0.3 & 6.0 & 420 & 56.786 & 60.014 & 5.378 \\
\hline 0.7 & 6.0 & 420 & 54.003 & 57.176 & 5.549 \\
\hline 1 & 6.0 & 420 & 53.263 & 56.211 & 5.244 \\
\hline 0.3 & 8.0 & 380 & 57.067 & 56.174 & 1.589 \\
\hline 0.7 & 8.0 & 380 & 54.175 & 54.408 & 0.428 \\
\hline 1 & 8.0 & 380 & 53.394 & 53.429 & 0.065 \\
\hline 0.3 & 8.0 & 400 & 60.069 & 58.532 & 2.626 \\
\hline 0.7 & 8.0 & 400 & 55.96 & 56.728 & 1.353 \\
\hline 1 & 8.0 & 400 & 54.744 & 55.179 & 0.788 \\
\hline 0.3 & 8.0 & 420 & 58.652 & 60.761 & 3.471 \\
\hline 0.7 & 8.0 & 420 & 55.032 & 58.037 & 5.177 \\
\hline 1 & 8.0 & 420 & 54.028 & 57.781 & 6.495 \\
\hline 0.3 & 10.0 & 380 & 61.055 & 56.476 & 8.107 \\
\hline 0.7 & 10.0 & 380 & 56.608 & 54.872 & 3.163 \\
\hline 1 & 10.0 & 380 & 55.246 & 54.292 & 1.757 \\
\hline 0.3 & 10.0 & 400 & 59.205 & 58.997 & 0.352 \\
\hline 0.7 & 10.0 & 400 & 55.373 & 56.811 & 2.531 \\
\hline 1 & 10.0 & 400 & 54.287 & 55.991 & 3.043 \\
\hline 0.3 & 10.0 & 420 & 62.27 & 61.165 & 1.806 \\
\hline 0.7 & 10.0 & 420 & 57.354 & 58.897 & 2.619 \\
\hline 1 & 10.0 & 420 & 55.815 & 58.048 & 3.846 \\
\hline
\end{tabular}


will be discussed in detail later in this study with regards to Arrhenius equation.

\section{Model validation}

The model equations for hydrotreating steps are simulated within gPROMS software. Process simulator predicts the behavior of chemical reactions and steps using standard engineering relationships, such as mass and energy balances, rate correlations, as well as phase and chemical equilibrium data.

The generated kinetic parameters obtained via optimization technique in ODS process are illustrated in Table 6. The minimization of the objective function, based on the sum of square errors between the experimental and calculated product compositions, was applied to find the best set of kinetic parameters.

Table 9 Comparison between experimental product composition and predicted product composition of light gasoil (LGO)

\begin{tabular}{|c|c|c|c|c|c|}
\hline LHSV & Press. & Temp. & Predicted & Experimental & Error\% \\
\hline 0.3 & 60 & 380 & 7.373 & 7.336 & 0.504 \\
\hline 0.7 & 60 & 380 & 3.803 & 5.002 & 23.970 \\
\hline 1 & 60 & 380 & 2.88 & 4.002 & 28.036 \\
\hline 0.3 & 60 & 400 & 7.716 & 8.453 & 8.718 \\
\hline 0.7 & 60 & 400 & 3.988 & 6.032 & 33.877 \\
\hline 1 & 60 & 400 & 3.016 & 4.981 & 39.450 \\
\hline 0.3 & 60 & 420 & 8.045 & 10.939 & 26.455 \\
\hline 0.7 & 60 & 420 & 4.176 & 8.013 & 47.884 \\
\hline 1 & 60 & 420 & 3.157 & 6.654 & 52.555 \\
\hline 0.3 & 80 & 380 & 8.79 & 7.942 & 10.677 \\
\hline 0.7 & 80 & 380 & 4.61 & 5.131 & 10.154 \\
\hline 1 & 80 & 380 & 3.482 & 4.121 & 15.506 \\
\hline 0.3 & 80 & 400 & 10.907 & 8.811 & 23.788 \\
\hline 0.7 & 80 & 400 & 6.001 & 6.215 & 3.443 \\
\hline 1 & 80 & 400 & 4.556 & 5.069 & 10.120 \\
\hline 0.3 & 80 & 420 & 8.733 & 11.308 & 22.771 \\
\hline 0.7 & 80 & 420 & 4.667 & 8.109 & 42.446 \\
\hline 1 & 80 & 420 & 3.539 & 6.981 & 49.305 \\
\hline 0.3 & 100 & 380 & 11.201 & 8.059 & 38.987 \\
\hline 0.7 & 100 & 380 & 6.271 & 5.332 & 17.610 \\
\hline 1 & 100 & 380 & 4.777 & 4.301 & 11.067 \\
\hline 0.3 & 100 & 400 & 9.343 & 9.225 & 1.2791 \\
\hline 0.7 & 100 & 400 & 4.965 & 6.467 & 23.225 \\
\hline 1 & 100 & 400 & 3.756 & 5.189 & 27.616 \\
\hline 0.3 & 100 & 420 & 11.953 & 11.397 & 4.878 \\
\hline 0.7 & 100 & 420 & 6.442 & 8.385 & 23.172 \\
\hline 1 & 100 & 420 & 4.871 & 7.105 & 31.442 \\
\hline
\end{tabular}

The comparison between experimental product and predicted product is illustrated in Tables 7, 8, 9, 10 and 11 . As shown in these tables, there is a large variation between predicted and experimental values; therefore, optimization has been applied on model parameters to minimize this variation. The experimental results versus simulation results obtained by optimization technique using gPROMS program are presented in Table 12. As can noticed from these results, the model is found to simulate the performance of the trickle bed reactor very well in the range of operating conditions studied with an SQE less than $5 \%$ among all the results obtained.

\section{Kinetic analysis of hydrotreating process}

The hydrotreating of RCR using trickle bed reactor was tested under various LHSV $\left(0.3-1 \mathrm{~h}^{-1}\right)$, temperature (653-693 K), and pressure (6, 8, $10 \mathrm{MPas})$ over $(\mathrm{Ni}-\mathrm{Mo} / \gamma$ -

Table 10 Comparison between experimental product composition and predicted product composition of kerosene $(K)$

\begin{tabular}{|c|c|c|c|c|c|}
\hline LHSV & Press. & Temp. & Predicted & Experimental & Error\% \\
\hline 0.3 & 60 & 380 & 0.562 & 1.193 & 52.892 \\
\hline 0.7 & 60 & 380 & 0.705 & 0.709 & 0.537 \\
\hline 1 & 60 & 380 & 0.404 & 0.548 & 26.277 \\
\hline 0.3 & 60 & 400 & 1.386 & 1.401 & 1.070 \\
\hline 0.7 & 60 & 400 & 0.668 & 0.961 & 30.489 \\
\hline 1 & 60 & 400 & 0.48 & 0.756 & 36.508 \\
\hline 0.3 & 60 & 420 & 1.686 & 2.096 & 19.561 \\
\hline 0.7 & 60 & 420 & 0.825 & 1.455 & 43.299 \\
\hline 1 & 60 & 420 & 0.596 & 1.198 & 50.250 \\
\hline 0.3 & 80 & 380 & 1.441 & 1.398 & 3.075 \\
\hline 0.7 & 80 & 380 & 0.716 & 0.832 & 13.942 \\
\hline 1 & 80 & 380 & 0.519 & 0.672 & 22.768 \\
\hline 0.3 & 80 & 400 & 2.111 & 1.717 & 22.947 \\
\hline 0.7 & 80 & 400 & 1.122 & 1.159 & 3.209 \\
\hline 1 & 80 & 400 & 0.827 & 0.936 & 11.645 \\
\hline 0.3 & 80 & 420 & 1.711 & 2.589 & 33.912 \\
\hline 0.7 & 80 & 420 & 0.858 & 1.794 & 52.173 \\
\hline 1 & 80 & 420 & 0.624 & 1.602 & 61.048 \\
\hline 0.3 & 100 & 380 & 2.618 & 1.641 & 59.536 \\
\hline 0.7 & 100 & 380 & 1.407 & 1.021 & 37.806 \\
\hline 1 & 100 & 380 & 1.042 & 0.821 & 26.918 \\
\hline 0.3 & 100 & 400 & 2.109 & 2.033 & 3.738 \\
\hline 0.7 & 100 & 400 & 1.899 & 1.406 & 35.064 \\
\hline 1 & 100 & 400 & 0.797 & 1.188 & 32.912 \\
\hline 0.3 & 100 & 420 & 3.004 & 3.141 & 4.361 \\
\hline 0.7 & 100 & 420 & 1.668 & 2.112 & 21.022 \\
\hline 1 & 100 & 420 & 1.244 & 1.798 & 30.812 \\
\hline
\end{tabular}


Table 11 Comparison between experimental product composition and predicted product composition of naphtha $(\mathrm{N})$

\begin{tabular}{|c|c|c|c|c|c|}
\hline LHSV & Press. & Temp. & Predicted & Experimental & Error\% \\
\hline 0.3 & 60 & 380 & 1.270 & 1.279 & 0.703 \\
\hline 0.7 & 60 & 380 & 0.611 & 0.801 & 23.720 \\
\hline 1 & 60 & 380 & 0.439 & 0.618 & 28.964 \\
\hline 0.3 & 60 & 400 & 1.575 & 2.328 & 32.345 \\
\hline 0.7 & 60 & 400 & 0.757 & 1.519 & 50.164 \\
\hline 1 & 60 & 400 & 0.544 & 1.201 & 54.704 \\
\hline 0.3 & 60 & 420 & 1.899 & 2.986 & 36.403 \\
\hline 0.7 & 60 & 420 & 0.924 & 1.995 & 53.684 \\
\hline 1 & 60 & 420 & 0.666 & 1.689 & 60.568 \\
\hline 0.3 & 80 & 380 & 2.251 & 1.626 & 38.438 \\
\hline 0.7 & 80 & 380 & 1.109 & 0.965 & 14.922 \\
\hline 1 & 80 & 380 & 0.802 & 0.755 & 6.225 \\
\hline 0.3 & 80 & 400 & 2.972 & 2.503 & 18.737 \\
\hline 0.7 & 80 & 400 & 1.562 & 1.691 & 7.628 \\
\hline 1 & 80 & 400 & 1.149 & 1.318 & 12.822 \\
\hline 0.3 & 80 & 420 & 2.514 & 3.486 & 27.883 \\
\hline 0.7 & 80 & 420 & 1.266 & 2.485 & 49.054 \\
\hline 1 & 80 & 420 & 0.921 & 1.998 & 53.904 \\
\hline 0.3 & 100 & 380 & 3.474 & 1.978 & 75.632 \\
\hline 0.7 & 100 & 380 & 1.87 & 1.204 & 55.315 \\
\hline 1 & 100 & 380 & 1.384 & 0.921 & 50.271 \\
\hline 0.3 & 100 & 400 & 2.999 & 2.877 & 4.240 \\
\hline 0.7 & 100 & 400 & 1.52 & 2.001 & 24.038 \\
\hline 1 & 100 & 400 & 1.108 & 1.618 & 31.520 \\
\hline 0.3 & 100 & 420 & 3.905 & 3.756 & 3.967 \\
\hline 0.7 & 100 & 420 & 2.106 & 2.764 & 23.806 \\
\hline 1 & 100 & 420 & 1.561 & 2.198 & 28.980 \\
\hline
\end{tabular}

$\mathrm{Al}_{2} \mathrm{O}_{3}$ ) to determine the reaction kinetics by analyzing the results obtained depending on experiments and using kinetic models within gPROMS program.

The increase in process yield happened due to the kinetic parameters used to describe hydrotreating processes in this model that are affected by the operating conditions. The reaction temperature influences the rate constant of hydrotreating processes, where increasing the reaction temperature leads to increase in the reaction rate constant defined by the Arrhenius equation so that increasing of temperature will increase the number of molecules involved in the oxidation reaction due to Arrhenius equation, which in return increases the yield.

Liquid hourly space velocity (LHSV) is also a significant operational factor that calculates the severity of reaction and the efficiency of hydrogenolysis. With the LHSV decreasing, the reaction rates will be significant. Decreasing LHSV described by liquid velocity means increasing residence time and increasing yield of light fractions.

\section{Activation energy}

According to Arrhenius equation, a plot of $(\ln K)$ versus (1/ $T)$ gives a straight line with slope equal to $\left(-E_{\mathrm{A}} / R\right)$, the activation energy is then calculated as illustrated in Fig. 7 as a sample of energy and frequency factor calculation. These values are within the range of the value in literatures $\left(E=202.4 \mathrm{~kJ} \mathrm{~mol}^{-1}\right.$ by Sanchez et al. [35]; $E=146.271 \mathrm{~kJ} \mathrm{~mol}^{-1}$ by Valavarasu et al. [36]; $E=104.52$; by Sadighiet al. [34]; $E=177.823$ by Sadighi [37]).

Also, there are many factors affecting the activation energy that can be summarized as follows:

One of the most important factors is operating pressure. The activation energies found in the present work are in partial agreement with those found in the literature. For Al, Humadia et al. [38] found a range of activation energies for different lumps $\left(8.1 \times 10^{4}-21.3 \times 10^{4} \mathrm{~kJ} \mathrm{~mol}^{-1}\right)$ at 120 bar and different operating conditions. However, Sánchez and Ancheyta [39] found closer values at different operating pressures $(6.9-9.8 \mathrm{MPa})$ of $131-276 \mathrm{~kJ} \mathrm{~mol}^{-1}$ with the same type of catalyst.

The modified Arrhenius equation was used to determine kinetic constants, as a function of both temperature and pressure:

$K=A \exp ^{(-E / R T)}\left(P / P^{\circ}\right)^{\beta}$

Many literatures have reported the dependency of $\mathrm{k}$ on pressure and temperature [40]. The experimental observation showed that pressure has highly affected hydrocracking reactions because the pressure-dependent parameter $(\beta)$ is far from unity (0.0177). Tables 13,14 and 15 show the effect of operational pressure on kinetic parameters.

The following observations are summarized on these values:

- Naphtha is produced exclusively from the conversion of residue, HGO, LGO and kerosene. It represents the main product, while HGO cracking contributes the least part in the formation of naphtha.

- The kinetic parameters of residue hydrotreating exhibit the following order:

$\mathrm{k}_{2}>\mathrm{k}_{1}>\mathrm{k}_{4}>\mathrm{k}_{3}$

This finding indicates a high selectivity towards LGO followed by HGO and kerosene whereas naphtha exhibits the lowest selectivity.

- A large part of residue is converted to HGO, while a small part is converted to other fractions. Therefore, the 


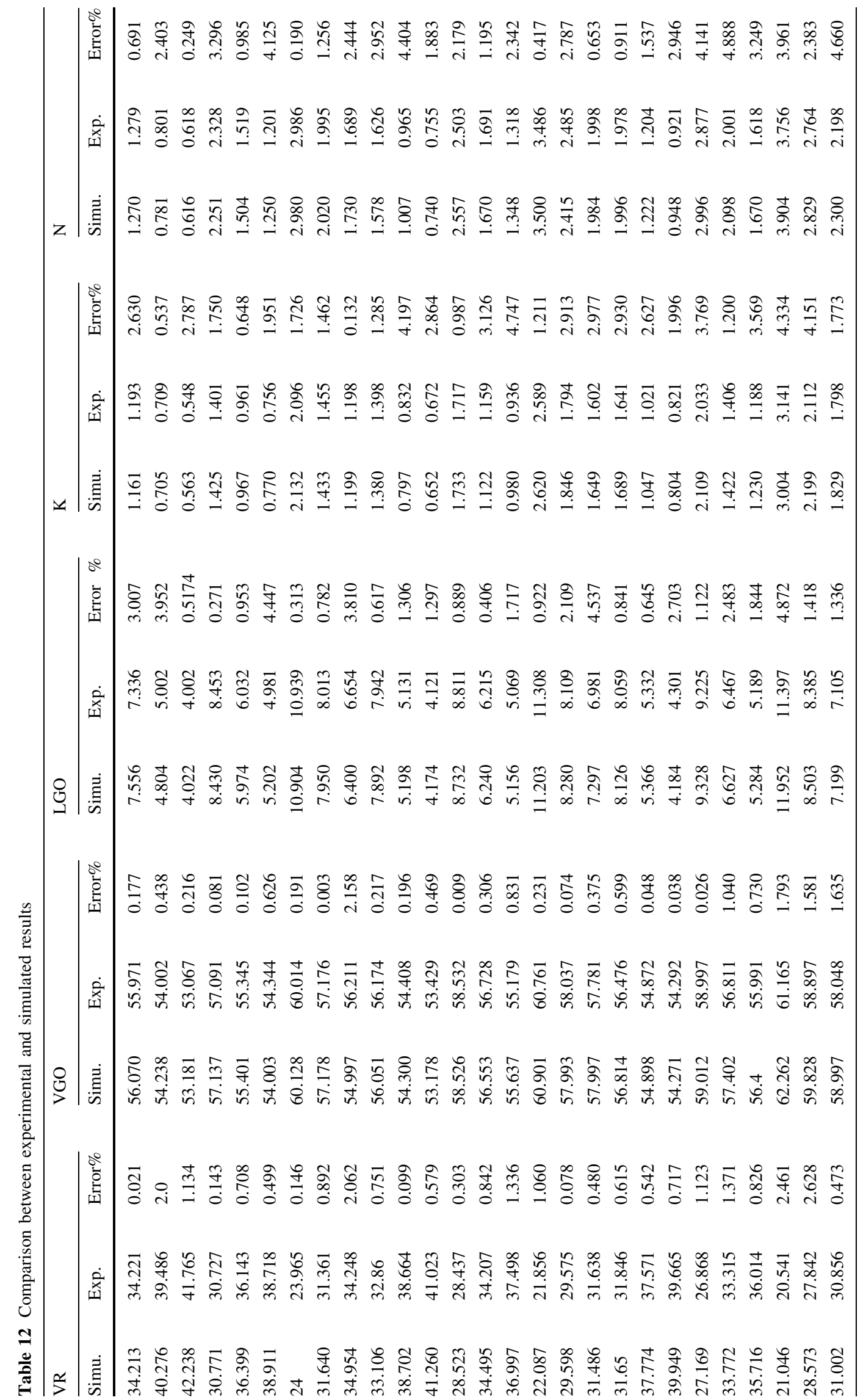



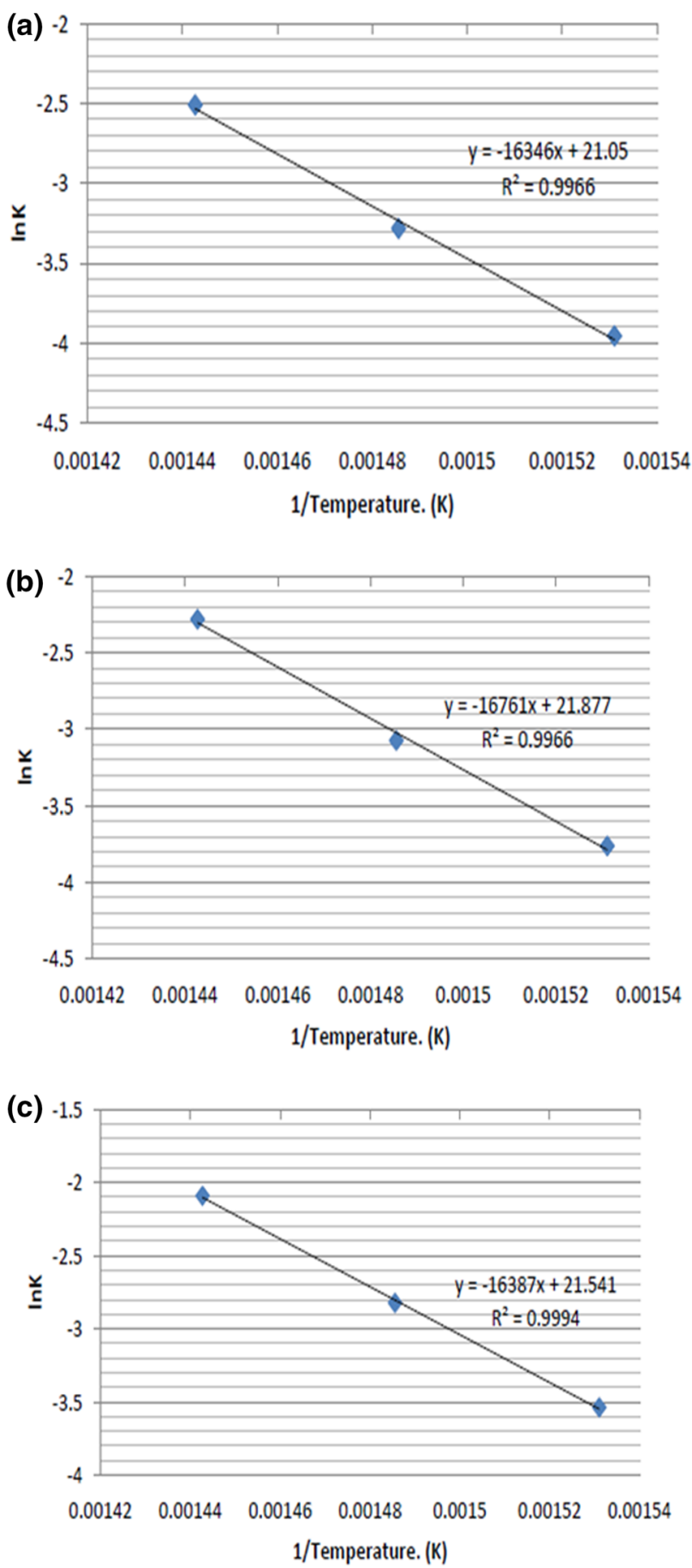

Fig. 7 Estimation of kinetic parameters from $k_{3}$ at different temperatures for constant pressure at a 6, b 8 and $\mathbf{c} 10 \mathrm{MPas}$

fraction of HGO is the highest percentage over the products.

- An increase in rate constant due to increase of temperature and pressure is observed for all fractions. This confirms the significant effect of thermal cracking and high hydrogen concentration in the reactor.
Table 13 Kinetic parameters at $\mathrm{P}=6 \mathrm{MPas}$

\begin{tabular}{|c|c|c|c|c|}
\hline $\mathrm{Ki}$ & $\begin{array}{l}\text { Reaction } \\
\text { rate } \\
\text { constant }\end{array}$ & $\begin{array}{l}\text { Activation } \\
\text { energy (Ea) } \\
\left(\mathrm{kJ} \mathrm{mol}^{-1}\right)\end{array}$ & $\begin{array}{l}\text { Frequency } \\
\text { factor }(A)\end{array}$ & $\begin{array}{l}\text { Unit of } \\
\text { frequency } \\
\text { factor }\end{array}$ \\
\hline K1, T1 & 0.077 & $1.37 \mathrm{E}+02$ & $7.219 \mathrm{E}+09$ & $1 /(\mathrm{wt} \%)^{0.179} \mathrm{~h}$ \\
\hline $\mathrm{K} 1, \mathrm{~T} 2$ & 0.015 & & & \\
\hline $\mathrm{K} 1, \mathrm{~T} 3$ & 0.335 & & & \\
\hline $\mathrm{K} 2, \mathrm{~T} 1$ & 0.112 & $1.17 \mathrm{E}+02$ & $263,614,931$ & $1 /(\mathrm{wt} \%)^{0.179} \mathrm{~h}$ \\
\hline $\mathrm{K} 2, \mathrm{~T} 2$ & 0.206 & & & \\
\hline $\mathrm{K} 2, \mathrm{~T} 3$ & 0.390 & & & \\
\hline $\mathrm{K} 3, \mathrm{~T} 1$ & 0.019 & $1.36 \mathrm{E}+02$ & $1.386 \mathrm{E}+09$ & $1 /(\mathrm{wt} \%)^{0.179} \mathrm{~h}$ \\
\hline K3, T2 & 0.037 & & & \\
\hline K3, T3 & 0.081 & & & \\
\hline $\mathrm{K} 4, \mathrm{~T} 1$ & 0.020 & $1.59 \mathrm{E}+02$ & $1.05 \mathrm{E}+11$ & $1 /(\mathrm{wt} \%)^{0.179} \mathrm{~h}$ \\
\hline $\mathrm{K} 4, \mathrm{~T} 2$ & 0.058 & & & \\
\hline $\mathrm{K} 4, \mathrm{~T} 3$ & 0.112 & & & \\
\hline $\mathrm{K} 5$, T1 & 0 & $6.69 \mathrm{E}+02$ & $8.79 \mathrm{E}+49$ & $1 /(\mathrm{wt} \%)^{0.984} \mathrm{~h}$ \\
\hline $\mathrm{K} 5, \mathrm{~T} 2$ & 0.001 & & & \\
\hline K5, T3 & 0.004 & & & \\
\hline K6, T1 & 0 & $5.39 \mathrm{E}+02$ & $5.75 \mathrm{E}+35$ & $1 /(\mathrm{wt} \%)^{0.984} \mathrm{~h}$ \\
\hline K6, T2 & 0 & & & \\
\hline K6, T3 & 0 & & & \\
\hline $\mathrm{K} 7, \mathrm{~T} 1$ & 0 & $4.05 \mathrm{E}+02$ & $1.90 \mathrm{E}+27$ & $1 /(\mathrm{wt} \%)^{0.984} \mathrm{~h}$ \\
\hline $\mathrm{K} 7, \mathrm{~T} 2$ & 0 & & & \\
\hline K7, T3 & 0 & & & \\
\hline $\mathrm{K} 8, \mathrm{~T} 1$ & 0 & $2.59 \mathrm{E}+02$ & $2.90 \mathrm{E}+17$ & $1 /(\mathrm{wt} \%)^{0.993} \mathrm{~h}$ \\
\hline $\mathrm{K} 8, \mathrm{~T} 2$ & 0.004 & & & \\
\hline K8, T3 & 0.005 & & & \\
\hline K9, T1 & 0 & $1.69 \mathrm{E}+02$ & $8.73 \mathrm{E}+09$ & $1 /(\mathrm{wt} \%)^{0.993} \mathrm{~h}$ \\
\hline K9, T2 & 0 & & & \\
\hline K9, T3 & 0 & & & \\
\hline $\mathrm{K} 10, \mathrm{~T} 1$ & 0.005 & $1.31 \mathrm{E}+02$ & $185,766,302$ & $1 /(\mathrm{wt} \%)^{0.023} \mathrm{~h}$ \\
\hline $\mathrm{K} 10, \mathrm{~T} 2$ & 0.016 & & & \\
\hline K10@ T3 & 0.020 & & & \\
\hline
\end{tabular}

- Kerosene yields are slightly higher than predicted yields from hydrotreating of the feed. This behavior has two explanations: the kerosene formation rate is almost equal to the kerosene hydrogenolysis rate, or kerosene formed by secondary cracking of heavy and light gas oil is insignificant.

- In general, the production of light fractions (LGO, kerosene and naphtha) from secondary cracking of products is slight. This is shown clearly from the values of reaction constants of LGO $\left(k_{5}\right)$, kerosene $\left(k_{6}\right.$ and $\left.k_{8}\right)$ and naphtha $\left(k_{7}, k_{9}\right.$ and $\left.k_{10}\right)$. This confirms the domination of thermal cracking and low catalyst selectivity toward production of kerosene and naphtha. 
Table 14 Kinetic parameters at $\mathrm{P}=8 \mathrm{MPas}$

\begin{tabular}{|c|c|c|c|c|}
\hline $\mathrm{Ki}$ & $\begin{array}{l}\text { Reaction } \\
\text { rate } \\
\text { constant }\end{array}$ & $\begin{array}{l}\text { Activation } \\
\text { energy } \\
(\mathrm{Ea}) \\
\left(\mathrm{kJ} \mathrm{mol}{ }^{-1}\right)\end{array}$ & $\begin{array}{l}\text { Frequency } \\
\text { factor }(A)\end{array}$ & $\begin{array}{l}\text { Unit of } \\
\text { Frequency } \\
\text { factor }\end{array}$ \\
\hline $\mathrm{K} 1, \mathrm{~T} 1$ & 0.079 & $1.46 \mathrm{E}+02$ & $4.03 \mathrm{E}+10$ & $1 /(\mathrm{wt} \%)^{0.179} \mathrm{~h}$ \\
\hline $\mathrm{K} 1, \mathrm{~T} 2$ & 0.193 & & & \\
\hline K1, T3 & 0.375 & & & \\
\hline $\mathrm{K} 2, \mathrm{~T} 1$ & 0.124 & $1.13 \mathrm{E}+02$ & $134,894,021$ & $1 /(\mathrm{wt} \%)^{0.179} \mathrm{~h}$ \\
\hline $\mathrm{K} 2, \mathrm{~T} 2$ & 0.22 & & & \\
\hline $\mathrm{K} 2, \mathrm{~T} 3$ & 0.229 & & & \\
\hline $\mathrm{K} 3, \mathrm{~T} 1$ & 0.023 & $1.39 \mathrm{E}+02$ & $3.148 \mathrm{E}+09$ & $1 /(\mathrm{wt} \%)^{0.179} \mathrm{~h}$ \\
\hline $\mathrm{K} 3, \mathrm{~T} 2$ & 0.046 & & & \\
\hline K3, T3 & 0.102 & & & \\
\hline $\mathrm{K} 4, \mathrm{~T} 1$ & 0.026 & $1.54 \mathrm{E}+02$ & $5.95 \mathrm{E}+10$ & $1 /(\mathrm{wt} \%)^{0.179} \mathrm{~h}$ \\
\hline $\mathrm{K} 4, \mathrm{~T} 2$ & 0.068 & & & \\
\hline K4, T3 & 0.136 & & & \\
\hline $\mathrm{K} 5, \mathrm{~T} 1$ & 0 & $3.56 \mathrm{E}+02$ & $5.69 \mathrm{E}+24$ & $1 /(\mathrm{wt} \%)^{0.984} \mathrm{~h}$ \\
\hline $\mathrm{K} 5, \mathrm{~T} 2$ & 0.002 & & & \\
\hline K5, T3 & 0.008 & & & \\
\hline K6, T1 & 0 & $5.64 \mathrm{E}+02$ & $9.92 \mathrm{E}+37$ & $1 /(\mathrm{wt} \%)^{0.984} \mathrm{~h}$ \\
\hline K6, T2 & 0 & & & \\
\hline K6, T3 & 0 & & & \\
\hline $\mathrm{K} 7, \mathrm{~T} 1$ & 0 & $5.73 \mathrm{E}+02$ & $2.13 \mathrm{E}+40$ & $1 /(\mathrm{wt} \%)^{0.984} \mathrm{~h}$ \\
\hline $\mathrm{K} 7, \mathrm{~T} 2$ & 0 & & & \\
\hline $\mathrm{K} 7, \mathrm{~T} 3$ & 0.001 & & & \\
\hline K8, T1 & 0.002 & $3.43 \mathrm{E}+02$ & $7.99 \mathrm{E}+24$ & $1 /(\mathrm{wt} \%)^{0.993} \mathrm{~h}$ \\
\hline $\mathrm{K} 8, \mathrm{~T} 2$ & 0.047 & & & \\
\hline K8, T3 & 0.081 & & & \\
\hline K9, T1 & 0 & $2.16 \mathrm{E}+02$ & $2.29 \mathrm{E}+13$ & $1 /(\mathrm{wt} \%)^{0.993} \mathrm{~h}$ \\
\hline K9, T2 & 0 & & & \\
\hline K9, Т3 & 0 & & & \\
\hline $\mathrm{K} 10, \mathrm{~T} 1$ & 0.003 & $1.36 \mathrm{E}+02$ & $248,263,192$ & $1 /(\mathrm{wt} \%)^{0.023} \mathrm{~h}$ \\
\hline $\mathrm{K} 10, \mathrm{~T} 2$ & 0.005 & & & \\
\hline K10, T3 & 0.015 & & & \\
\hline
\end{tabular}

\section{Conclusion}

Hydrotreating of RCR was modeled by a discrete kinetic model. Hydrotreating of RCR is simulated according to kinetic parameters estimated from previous works; results of this simulation give a large error percent between predicted and experimental compositions of fractions. Therefore, the optimization of kinetic model to minimize an objective function and decrease error percent between predicted and experimental compositions is applied. The optimal values of kinetic parameters are calculated and implemented in the simulation. The results of application of optimal kinetic parameters results in a good agreement between predicted and experimental compositions and the error percent less than $5 \%$ which is satisfactory. Pressure
Table 15 Kinetic parameters at $P=10$ MPas

\begin{tabular}{|c|c|c|c|c|}
\hline $\mathrm{Ki}$ & $\begin{array}{l}\text { Reaction } \\
\text { rate } \\
\text { constant }\end{array}$ & $\begin{array}{l}\text { Activation } \\
\text { energy } \\
(\mathrm{Ea}) \\
\left(\mathrm{kJ} \mathrm{mol}^{-1}\right)\end{array}$ & $\begin{array}{l}\text { Frequency } \\
\text { factor (A) }\end{array}$ & $\begin{array}{l}\text { Unit of } \\
\text { frequency } \\
\text { factor }\end{array}$ \\
\hline $\mathrm{K} 1, \mathrm{~T} 1$ & 0.093 & $1.46 \mathrm{E}+02$ & $4.37 \mathrm{E}+10$ & $1 /(\mathrm{wt} \%)^{0.179} \mathrm{~h}$ \\
\hline $\mathrm{K} 1, \mathrm{~T} 2$ & 0.212 & & & \\
\hline $\mathrm{K} 1, \mathrm{~T} 3$ & 0.44 & & & \\
\hline $\mathrm{K} 2, \mathrm{~T} 1$ & 0.126 & $1.03 \mathrm{E}+02$ & $20,999,307$ & $1 /(\mathrm{wt} \%)^{0.179} \mathrm{~h}$ \\
\hline $\mathrm{K} 2, \mathrm{~T} 2$ & 0.229 & & & \\
\hline $\mathrm{K} 2, \mathrm{~T} 3$ & 0.375 & & & \\
\hline $\mathrm{K} 3$, T1 & 0.029 & $1.36 \mathrm{E}+02$ & $2.263 \mathrm{E}+09$ & $1 /(\mathrm{wt} \%)^{0.179} \mathrm{~h}$ \\
\hline $\mathrm{K} 3$, T2 & 0.059 & & & \\
\hline K3, T3 & 0.123 & & & \\
\hline $\mathrm{K} 4, \mathrm{~T} 1$ & 0.034 & $1.41 \mathrm{E}+02$ & $7.076 \mathrm{E}+09$ & $1 /(\mathrm{wt} \%)^{0.179} \mathrm{~h}$ \\
\hline $\mathrm{K} 4, \mathrm{~T} 2$ & 0.081 & & & \\
\hline K4, T3 & 0.152 & & & \\
\hline $\mathrm{K} 5$, T1 & 0.005 & $2.41 \mathrm{E}+02$ & $9.67 \mathrm{E}+16$ & $1 /(\mathrm{wt} \%)^{0.984} \mathrm{~h}$ \\
\hline K5, T2 & 0.015 & & & \\
\hline K5, T3 & 0.069 & & & \\
\hline K6, T1 & 0 & $6.32 \mathrm{E}+02$ & $8.08 \mathrm{E}+43$ & $1 /(\mathrm{wt} \%)^{0.984} \mathrm{~h}$ \\
\hline K6, T2 & 0 & & & \\
\hline K6, T3 & 0 & & & \\
\hline $\mathrm{K} 7, \mathrm{~T} 1$ & 0 & $3.15 \mathrm{E}+02$ & $7.38 \mathrm{E}+20$ & $1 /(\mathrm{wt} \%)^{0.984} \mathrm{~h}$ \\
\hline $\mathrm{K} 7, \mathrm{~T} 2$ & 0 & & & \\
\hline $\mathrm{K} 7, \mathrm{~T} 3$ & 0 & & & \\
\hline $\mathrm{K} 8, \mathrm{~T} 1$ & 0.001 & $2.62 \mathrm{E}+02$ & $2.10 \mathrm{E}+18$ & $1 /(\mathrm{wt} \%)^{0.993} \mathrm{~h}$ \\
\hline $\mathrm{K} 8, \mathrm{~T} 2$ & 0.011 & & & \\
\hline $\mathrm{K} 8, \mathrm{~T} 3$ & 0.03 & & & \\
\hline K9, T1 & 0.002 & $1.25 \mathrm{E}+02$ & $21,856,305$ & $1 /(\mathrm{wt} \%)^{0.993} \mathrm{~h}$ \\
\hline K9, T2 & 0.003 & & & \\
\hline K9, T3 & 0.01 & & & \\
\hline $\mathrm{K} 10, \mathrm{~T} 1$ & 0.011 & $1.56 \mathrm{E}+02$ & $3.33 \mathrm{E}+10$ & $1 /(\mathrm{wt} \%)^{0.023} \mathrm{~h}$ \\
\hline $\mathrm{K} 10, \mathrm{~T} 2$ & 0.03 & & & \\
\hline K10, T3 & 0.057 & & & \\
\hline
\end{tabular}

has a significant effect on hydrogenolysis reactions of RCR that is shown from the optimal value in order of pressure term in modified Arrhenius equation $(\beta)$, whereas the optimal value of $(\beta)$ is $(0.0177)$.

Open Access This article is distributed under the terms of the Creative Commons Attribution 4.0 International License (http:// creativecommons.org/licenses/by/4.0/), which permits unrestricted use, distribution, and reproduction in any medium, provided you give appropriate credit to the original author(s) and the source, provide a link to the Creative Commons license, and indicate if changes were made.

\section{References}

1. Ward JW (1993) Hydrocracking processes and catalysts. Fuel Process Technol 35:55-85 
2. Meyers RA (1996) Handbook of petroleum refining processes. Third edition: Chapter 8, McGrow Hill

3. Sadighi S, Ahmad A, Rashidzadeh M (2010) 4-Lump kinetic model for vacuum gas oil hydrocracker involving hydrogen consumption. Korean J Chem Eng 27(4):1099-1108

4. Bionda SK, Gomzi Z, Saric T (2005) Testing of hydrosulfurization process in small trickle-bed reactor. Chem Eng $J$ 106:105-110

5. Laxminarasimhan CS, Verma RP, Ramachandran PA (2004) Continuous lumping model for simulation of hydrocracking. AIChE J 42:2645

6. Khorasheh F, Zainali H, Chan EC, Gray MR (2001) Kinetic modeling of bitumen hydrocracking reactions. Pet Coal 43:208

7. Khorasheh F, Chan EC, Gray MR (2005) Development of a continuous kinetic model for catalytic hydrodesulfurization of bitumen. Pet Coal 47:39

8. Ashuri E, Khorasheh F, Gray MR (2007) Development of a continuous kinetic model for catalytic hydrodenitrogenation of bitumen. Scientia Iranica 14:152

9. Schweitzer JM, Galtier P, Schweich D (1999) A single events kinetic model for the hydrocracking of paraffins in a three-phase reactor. Chem Eng Sci 54:2441-2452

10. Bhutani N, Rangaiah GP, Ray AK (2006) First-Principles, DataBased, and Hybrid Modeling and Optimization of an Industrial Hydrocracking Unit. Ind Eng Chem Res 45:7807-7816

11. Balasubramanian P, Pushpavanam S (2008) Model discrimination in hydrocracking of vacuum gas oil using discrete lumped kinetics. Fuel 87:1660-1672

12. Stangeland B (1974) A kinetic model for the prediction of hydrocracker yields. Ind Eng Chem Process Des Dev 13(1):71-76

13. Krishna R, Saxena AK (1989) Use of an Axial-Dispersion Model for Kinetic Description of Hydrocracking. Chem Eng Sci 44(3):703-712

14. Haitham M, Lababidi S, Al Humaidan F (2011) Modeling the Hydrocracking Kinetics of Atmospheric Residue in Hydrotreating, Processes by the Continuous Lumping Approach. Energy Fuels 25:1939-1949

15. Astarita G, Sandler SI (1991) Kinetics and thermodynamics lumping of multicomponent mixtures. Elsevier, Amsterdam, pp 111-129

16. Laxminarasimhan CS, Verma RP, Ramachandran PA (1996) Continuous lumping model for simulation of hydrocracking. AIChE J 42:2645-2659

17. Sadighi S, Ahmad A, Masoodian SK (2012) Effect of Lump Partitioning on the Accuracy of a Commercial Vacuum Gas Oil Hydrocracking Model. Int J Chem React Eng 10(1)

18. Wordu AA, Akpa JG (2014) Modeling of Hydro-Cracking Lumps of Series-Parallel Complex Reactions in Plug Flow Reactor Plant. Eur J Eng Tech 2:1

19. Rashidzadeh M, Ahmad A, Sadighi S (2011) Studying of Catalyst Deactivation in a Commercial Hydrocracking Process (ISOMAX). J Pet Sci Tech 1:46-54

20. Longnian H, Xiangchen F, Chong P, Tao Z (2013) Application of Discrete Lumped Kinetic Modeling on Vacuum Gas Oil Hydrocracking. China Petrol Process Petrochem Technol Simul Optim 15(2):67-73

21. Becker J, Celse B, Guillaume D, Dulot H, Costa V (2015) Hydrotreatment modeling for a variety of VGO feedstocks: a continuous lumping approach. Fuel 139:133-143
22. Bej ShK, Dalai AK, Adjaye J (2001) Comparison of hydrodenitrogenation of basic and non-basic nitrogen compounds present in oil sands derived heavy gas oil. Energy Fuels 15:377-383

23. Khalfhallah HA (2009) Modelling and optimization of Oxidative Desulfurization Process for Model Sulfur Compounds and Heavy Gas Oil. PhD Thesis. University of Bradford

24. Macías MJ, Ancheyta J (2004) Simulation of an isothermal hydrodesulfurization small reactor with different catalyst particle shapes. Catal Today 98:243

25. Alvarez A, Ancheyta J (2008) Simulation and Analysis of Different Quenching Alternatives for an Industrial Vacuum Gasoil Hydrotreater. Chem Eng Sci 63:662-673

26. Ancheyta J (2011) Modeling and Simulation of Catalytic Reactors for Petroleum refining. Wiley, New Jersey

27. Mohanty S, Saraf D, Kunzru D (1991) 4-Lump kinetic model for vacuum gas oil hydrocracker involving hydrogen consumption. Fuel Process Tech 29:1

28. gPROMS. Process Systems Enterprise, gPROMS. http://www. psenterprise.com/gproms, 1997-2015

29. Poyton AA, Varziri MS, McAuley KB, McLellan PJ, Ramsay JO (2006) Parameter estimation in continuous-time dynamic models using principal differential analysis. Comput Chem Eng 30:698-708

30. Jarullah AT, Iqbal MM, Wood AS (2010) Kinetic parameter estimation and simulation of trickle-bed reactor for hydrodesulfurization of crude oil. Chem Eng Sci 66:859-871

31. Jarullah AT, Iqbal MM, Wood AS (2011) Kinetic model development and simulation of simultaneous hydrodenitrogenation and hydrodemetallization of crude oil in trickle bed reactor. Fuel 90:2165-2181

32. Jarullah AT, Iqbal MM, Wood AS (2012) Improving fuel quality by whole crude oil hydrotreating: a kinetic model for hydrodeasphaltenization in a trickle bed reactor. Applied Energy 94:182-191

33. Panariti N, Del Bianco A, Del Piero G, Marchionna M (2000) Petroleum Residue Upgrading with Dispersed Catalysts: Part 1. Catalysts Activity and Selectivity. Appl Catal A 204:203-213

34. Sadighi S, Ahmad A, Rashidzadeh M (2010) 4-Lump kinetic model for vacuum gas oil hydrocracker involving hydrogen consumption. Korean J Chem Eng 27(4):1099-1108

35. Sánchez S, Pacheco R, Sánchez A, La Rubia MD (2005) Thermal Effects of CO2 Absorption in Aqueous Solutions of 2-Amino-2methyl-1-propanol. AIChE Journal 51(10):2769-2777

36. Valavarasu G, Bhaskar M, Sairam B, Balaraman KS, Balu K (2005) A Four Lump Kinetic Model for the Simulation of the Hydrocracking Process. Pet Sci Tech 23:11-12

37. Sadighi S (2013) Modeling A Vacuum Gas Oil Hydrocracking Reactor Using Axial dispersion Lumped kinetics. Pet Coal 55(3):156-168

38. Al Humaidan F, Lababidi H, Al Adwani H (2010) Hydrocracking of Atmospheric Residue Feed Stock in Hydrotreating Processing. Kwait Sci Eng 38(10):129-159

39. Sánchez S, Ancheyta J (2007) Effect of Pressure on the Kinetics of Moderate Hydrocracking of Maya Crude Oil. Energy Fuels 21(2):653-661

40. Jenkins JH, Stephens TW (1980) Hydrocarbon Process 11:163 